\title{
EFFECT OF CNG IN A FUEL DOSE ON THE COMBUSTION PROCESS OF A COMPRESSION-IGNITION ENGINE
}

\author{
Maciej Mikulski ${ }^{1}$, Sławomir Wierzbicki ${ }^{2}$, Michał Śmieja ${ }^{3}$, Jonas Matijošius ${ }^{4}$ \\ ${ }^{1,2,3}$ Dept of Mechatronics and Technical Education Informatics, \\ University of Warmia and Mazury in Olsztyn, Poland \\ ${ }^{4}$ Dept of Automobile Transport, Vilnius Gediminas Technical University, Lithuania
}

Submitted 20 June 2014; resubmitted 7 October 2014; accepted 18 November 2014

\begin{abstract}
Currently, one of the major trends in the research of contemporary combustion engines involves the potential use of alternative fuels. Considerable attention has been devoted to methane, which is the main component of Natural Gas (NG) and can also be obtained by purification of biogas. In compression-ignition engines fired with methane or Compressed Natural Gas (CNG), it is necessary to apply a dual-fuel feeding system. This paper presents the effect of the proportion of CNG in a fuel dose on the process of combustion. The recorded time series of pressure in a combustion chamber was used to determine the repeatability of the combustion process and the change of fuel compression-ignition delay in the combustion chamber. It has been showed that NG does not burn completely in a dual-fuel engine. The best conditions for combustion are ensured with higher concentrations of gaseous fuel. NG ignition does not take place simultaneously with diesel oil ignition. Moreover, if a divided dose of diesel is injected, NG ignition probably takes place at two points, as diesel oil.
\end{abstract}

Keywords: compression-ignition engine; dual fuel engine; CNG; combustion process; fuel.

\section{Introduction}

Reduced resources of oil as well as its continuously increasing prices necessitate seeking new alternative sources of energy. Such actions are stimulated by increasing environmental awareness and associated with efforts aimed at reducing emissions of toxic substances released to the atmosphere by combustion engines (Wierzbicki 2014).

Gaseous fuels are the kind of fuels whose share in the overall energy balance is set to grow. Among potential gaseous fuels applicable in transport, industry and energy sector, Natural Gas (NG) will be the most important because of its relatively large resources (BP p.l.c. 2013). Biogas is another fuel whose consumption is predicted to grow (BP p.l.c. 2013). Both NG and biogas have methane as their main component; it is the simplest hydrocarbon with the lowest content of carbon. NG contains up to $95 \%$ of methane, whereas its content in biogas ranges from 45 to $75 \%$. Biogas is frequently purified, which results in biomethane containing over $90 \%$ of methane (Makarevičienè et al. 2013).

Owing to a high octane number, methane-containing fuels can be used directly in spark-ignition engines.
The use of methane is more difficult in compressioncombustion engines, whose overall efficiency is much higher. This is caused mainly by a high temperature of auto-ignition (about $900 \mathrm{~K}$ ), which cannot be achieved in the compression stroke in diesel engines. Therefore, ignition of gaseous fuel requires the use of an external source of ignition. The most common way of inducing it is by injection of a dose of liquid fuel, which autoignites and acts as a source of ignition for the gaseous fuel (Wierzbicki 2014).

Intensive development of gaseous engines, including dual-fuel engines, has resulted in a large number of studies (Doijode et al. 2013; Makarevičienè et al. 2013; Ray et al. 2013) on the process of combustion and the effect of gas on the parameters of engine operation. The very presence of NG in a cylinder considerably affects the thermodynamic parameters of the charge during the compression process. Compression of air-gas mixture produces much lower temperatures than compression of pure air (Karim et al. 1989). The differences result from different physical and chemical properties of the gases - smaller proper heat and thermal conductivity. When stoichiometric mixtures of Compressed Natural

Corresponding author: Sławomir Wierzbicki

E-mail: slawekw@uwm.edu.pl 
Gas (CNG) are compressed, the temperatures achieved at the end of the process were lower by approx. 100 degrees compared to the compression of pure air. The period of ignition delay depends heavily on the temperature and pressure (Doijode et al. 2013; Goto et al. 2000) and - to a lesser extent - on the presence of oxygen in the mixture (Yao et al. 2009). In consequence, the presence of gas in the cylinder must result in an increased compression-ignition delay in a dual-fuel engine compared to one fuelled with diesel alone.

For most gaseous fuels, the delay of the start of the combustion process increases with their concentration in the charge (Karim et al. 1989). The opposite effect is observed for highly reactive gases, such as hydrogen or ethane, whose presence may shorten the ignition delay period (Azimov et al. 2012). This trend is an effect of the high activity of gas in pre-flame reactions and the formation of compression-ignition foci before a diesel oil injection.

The study (Aesoy, Valland 1996) has confirmed the hypothesis that the total ignition delay depends on the composition of a gas-air mixture. For mixtures of NG with air, the authors achieved a nearly twice-smaller ignition delay angle than when pure methane was used to make a mixture.

It has been proven (Raine 1990) that the relationships used to predict the compression-ignition delay in typical compression-ignition engines cannot be applied in dual-fuel systems. This conclusion has been corroborated by the results of studies, in which the compressionignition delay was larger by as much as $15^{\circ} \mathrm{CA}$, which could not be reflected by any of the known correlations. Subsequent studies (Liu, Karim 1995; Assanis et al. 2003) have confirmed the thesis.

On the other hand, however, other studies (Saito et al. 1999, 2000) have shown that the increase in the compression-ignition delay is smaller at higher temperatures. The authors of the studies conducted their experiments controlling the temperature at the beginning of the injection by heating the charge aspired into the engine cylinder. When the mixture was initially heated up to a temperature of $323 \mathrm{~K}$, the increase in the compression-ignition delay did not exceed $1.3^{\circ} \mathrm{CA}$, regardless of the charge. Therefore, it seems that in modern compression-ignition engines, with a high degree of compression and high temperatures reached during the process of compression, the reactivity of individual gases has a minor effect on the ignition delay. An increase in the compression-ignition delay in such a system is caused mainly by lower pressure and temperature during the injection when the mixture of air and gas is fed to the engine.

Changes of gas composition can significantly affect both the compression-ignition delay and the operation of the whole engine. Some authors (Motyl, Lisowski 2008) have examined the effect of the mixture composition on combustion in biogas-fired HCCI engines. The temperature and composition of a mixture have been found to have a significant effect on the maximum pressure of combustion, the temperature and pressure growth rate after compression-ignition and its delay. It has been shown that there is a limit of the initial temperature, which when exceeded results in the absence of any changes in the operational parameters of the engine work. The authors concluded that the temperature and composition of the fuel mixture may be used as regulation parameters of an HCCI engine.

Another study (Czerwinski, Comte 2001) examined the effect of quick changes of the gas composition on the operation of a spark-ignition engine fired with NG; it was shown that in such cases, the power, efficiency and emissivity of an engine may change. Moreover, considerable amounts of non-flammable components of gas made the work of an engine uneven. If a pilot dose is used in an engine, the smaller the 'gaseous fuel/diesel oil' ratio, the more similar the effect of changes of the gas composition will be to that observed in a spark-ignition engine.

Recent years have seen intensification of work aimed at investigating the effect of the gas composition on the process of combustion, especially in regard to low-calorific gases (Korakianitis et al. 2011; Saleh 2008). The parameters of engine operation with such fuels can be improved considerably by a small addition of hydrogen (Korakianitis et al. 2011).

The research, both theoretical and experimental, on the effect of the index of air excess in a gas-air mixture on the work of a dual-fuel engine fired with NG was also conducted by Stelmasiak (2004). He showed that the proper regulation of the parameter can result in gas combustion at a rate, which is twice lower compared to the combustion of diesel oil, which helps to reduce the emission of nitrogen oxides.

A number of authors (Badr et al. 1999; Stelmasiak 2003) have emphasised that the most beneficial conditions for combustion in multi-fuel engines are achieved when rich gas-air mixtures are used, achievable for high loads. The mixture then burns fast, which results in high thermal efficiency. For smaller loads, the gas content in the mixture must be considerably reduced, which results in lower combustion parameters. Poor mixtures burn slowly, which may result in flame extinguishing farther away from the stream of burning diesel oil and, in effect, to incomplete burning. In effect, the engine efficiency is reduced and the emission of $\mathrm{CO}$ and unburned hydrocarbons is increased. The process of combustion of poor mixtures can be made more efficient by increasing the pilot dose or by increasing the quality of spraying the stream of liquid fuel (higher pressure of injection, optimisation of spraying nozzles) (Saleh 2008; Semin, Bakar 2009; Semin et al. 2009). The process of combustion is greatly affected by homogenisation and layering of the load in the cylinder, which can be influenced by changes in the structure of the inlet system and by direct injection of gas (Jemni et al. 2011).

Modern CI engines have complex control algorithms, which implement different strategies depending on operating conditions of the engine. There are very few research results available on the process of NG combustion in modern, supercharged, dual-fuel engines 
(Wierzbicki 2014). In particular, the possibility of division of initial dosage of diesel hasn't been explored yet. Divided injection allows for controlling combustion process, reducing toxic emissions and noise reduction (Carlucci et al. 2003). In such a system, usually a very small portion of diesel (pilot dose) is injected early in the compression phase to improve the conditions for the main dose combustion, which is injected slightly after pilot dose ignition.

The aim of the present work was to determine the effect of the feeding of CNG to a CI engine controlled by a standard, modern Common Rail-type diesel injection system, which includes division of injection in two doses.

\section{The Research Stand and Methodology of the Experiment}

The engines used in the experiments described above were controlled mechanically or by special laboratory electronic control systems. Such an approach is obviously reasonable because it helps to explore and describe the processes which take place when fuel is fed to an engine in this manner.

However, it should be borne in mind that relatively high prices of fuel encourage users to seek ways of reducing the costs of vehicle exploitation. It is especially important for large engines, where reduction of costs by several percent results in a considerable decrease in the cost of vehicle fleet operation.

One of such methods is the use of special systems of feeding gaseous fuel to an engine. Despite the relatively low percentage of CNG (several dozen percent), such a system will payoff relatively soon, provided a vehicle is used intensively.

CNG feeding in such solutions is controlled by a special, dedicated controller, whereas the liquid fuel injection is controlled by the original controller. Factoryinstalled controllers are optimized for exhaust gas emission only for liquid fuels.
The process of combustion changes dramatically for such method of fuelling, which affects the engine operation and performance. Complex control strategies are often implemented in modern engines, where a fuel dose is divided into several smaller doses, which makes the process of combustion indirectly controllable.

If gaseous fuel is fed to the combustion chamber of such an engine, its combustion starts with the combustion of the first dose of the liquid fuel. Burning NG significantly changes the combustion process of potential subsequent doses of the liquid fuel. However, it should be borne in mind that both the programmed moment of diesel injection and its duration, do not take into account the dose of the gaseous fuel fed to the combustion chamber.

The aim of the experiment described below was to determine the effect of CNG feeding to an engine controlled by a standard modern Common Rail-type feeding system. The experiment was conducted on a four-cylinder ADCR compression-ignition engine, manufactured by Andoria-Mot (Table 1, Fig. 1). The engine

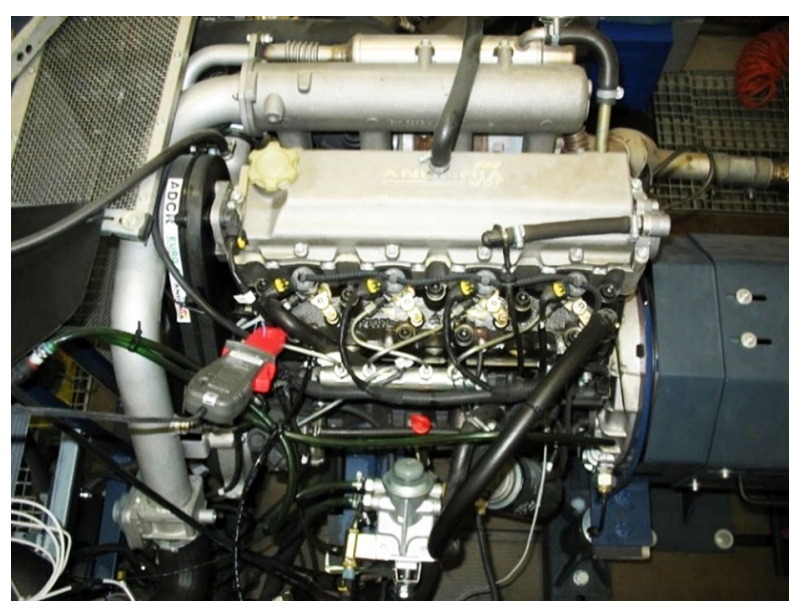

Fig. 1. An ADCR engine manufactured by Andoria-Mot

Table 1. Technical details of an ADCR engine

\begin{tabular}{ll}
\hline \multicolumn{1}{c}{ Engine } & \multicolumn{1}{c}{ ADCR } \\
\hline Type & diesel, 4-stroke, turbocharged with intercooler \\
\hline Fuel injection & Common Rail fuel accumulator system \\
\hline Engine layout & 4 cylinder inline, vertical \\
\hline Cylinder diameter/piston travel & $94 / 95 \mathrm{~mm}$ \\
\hline Piston displacement volume & $2636 \mathrm{~cm} 3$ \\
\hline Compression ratio & $17.5: 1$ \\
\hline Rated power $/$ rotational speed & $85 \mathrm{~kW} / 3700 \mathrm{rpm}$ \\
\hline Max. torque $/$ rotational speed & $250 \mathrm{Nm} / 1800-2200 \mathrm{rpm}$ \\
\hline Min. idle rotational speed & $750 \mathrm{rpm}$ \\
\hline Fuel consumption at torque peak ${ }^{*}$ & $210 \mathrm{~g} / \mathrm{kWh}$ \\
\hline Injection system $($ Bosch) & accumulator injection system $($ Common Rail) CR 2.0 \\
\hline Turbocharger & radial, with exhaust extraction valve \\
\hline EGR system & pneumatic EGR valve with exhaust cooler \\
\hline
\end{tabular}

Note: ${ }^{\star}$ according to ISO 1585:2010. 
is fitted out with a CR 2.0 injection system developed by Bosch and controlled by an EDC16C39 controller. Depending on the conditions of engine operation, a controller of this type follows two different strategies of fuel injection. A divided injection is performed at low rotational speeds and at low load, within the range of medium rotational speeds. Under other conditions, a single fuel dose is injected.

The engine used in the experiment was installed at the engine test stand (Fig. 2), operating at the Department of Mechatronics and Technical Education Informatics of the University of Warmia and Mazury in Olsztyn (Poland). The test stand consisted of the following elements:

- eddy current brake (AVL DynoPreform 240);

- a system of controlling the engine rotation speed (THA100);

- a fuel consumption measurement system as fuel scales (AVL 735S);

- an air flow measurement system (flow meter, filter, slotted line);

- a set of temperature sensors, PT100 type (cooling down water, oil, inlet air - after the intercooler);

- a test bed control and data acquisition system (PUMA Open).

In order to carry out the experiment, an engine was installed on the test bed and connected to the measuring equipment.

The engine was fitted out with a system of CNG feeding to the intake manifold before the turbocharger. The CNG feeding system consisted of a CNG tank, from which gas was delivered to a two-step reducer. During the first step, the gas was expanded to the pressure of 8.5 bar, during the second step its pressure was reduced to 2 bar. Gas flow is controlled through a flow rate regulator, from which gas is delivered to a mixer in the engine

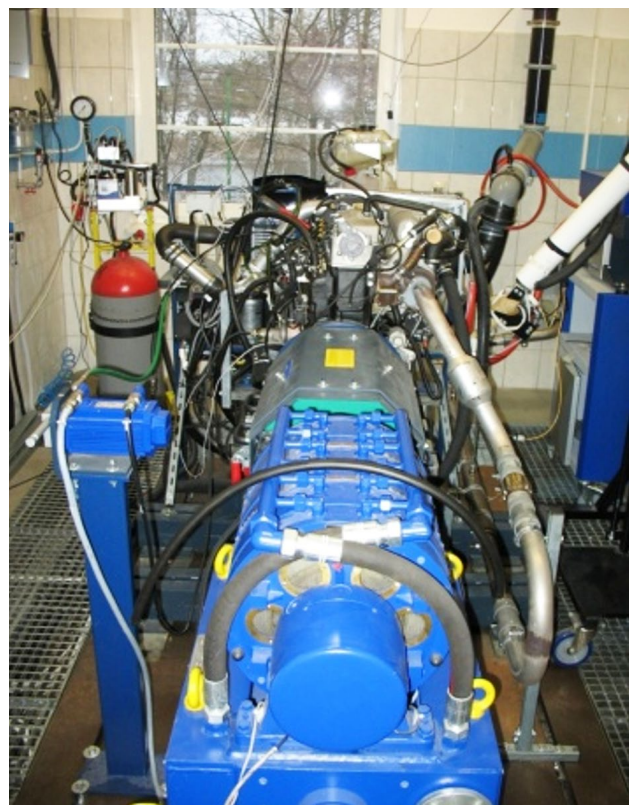

Fig. 2. The test stand with an ADCR engine installed at the engine test stand intake manifold, before the turbocharger, where the airfuel mixture is formed.

CNG with calorific value of $31.0 \mathrm{MJ} / \mathrm{m}^{3}$ and the heat of combustion of $39.5 \mathrm{MJ} / \mathrm{m}^{3}$ has been used in the experiment. The chemical composition of the tested gaseous fuel was as follows:

- methane - 97.8\%;

- ethane, propane, butane - $1 \%$;

- nitrogen $-1 \%$.

- carbon dioxide $-0.2 \%$.

Changes of pressure within the cylinder were recorded during the experiment. This was done with a piezoelectric pressure sensor (Type 6056A manufactured by Kistler) installed in one of the cylinders instead of the glow plug. The sensor was coupled with a Type 5018A charge amplifier and connected through a DAQ card to a PC. The software for data acquisition was developed based on the National Instruments - Labview environment. Correlation of fast changing pressure signal and the crankshaft angle were ensured by an optical encoder installed on the crankshaft. The resolution of the angle marker was 720 points/rotation, which made it possible to record pressure every $0.5^{\circ}$ of a crankshaft rotation, within a full engine work cycle.

For each measurement point, after stabilization of engine's operation parameters, pressure versus crank angle $\alpha$ for 100 cycles was recorded. Pressure measurement results where then cycle-averaged giving $p_{\text {avg }}(\alpha)$. Standard deviation has been used to calculate average error of pressure measurement for each crank angle $\delta p_{\text {avg }}(\alpha)$. On this basis, average relative error $\delta p_{\text {avg_r }}(\alpha)$ was calculated:

$$
\delta p_{\text {avg } r}(\alpha)=\frac{\delta p_{\text {avg }}(\alpha)}{p_{\text {avg }}(\alpha)} \cdot 100 \%
$$

as an estimate of engine's operation repeatability.

Additionally, in order to establish the moment of fuel injection at the injector of the dedicated cylinder, current clamps were installed, owing to which current changes in the injector coil could be recorded. The injector coil current signal was analysed the same way as described for a pressure signal.

The ignition start angle was determined by analysing changes of the second derivative of pressure in the cylinder. The maximum acceleration of the pressure growth determined the moment of ignition (Piętak, Mikulski 2011).

The engine rotation speed and torque were stabilized during the experiment for each measurement point with an accuracy of $\pm 5 \mathrm{rpm}$ and $\pm 2 \mathrm{Nm}$, respectively. The cooling water and lube oil temperatures were kept at constant $85 / 95 \pm 1^{\circ} \mathrm{C}$.

During the experiment, a specific amount of CNG was fed to the engine; its flow rate was regulated by a mass gas flow meter MASS-STREAM D-6371-DR. The fuel dose and the parameters of its injection (injection was regulated by the engine EDC16C39 controller).

The following were recorded during the experiment: the mass of air aspired by the engine $G_{P}$, consumption of diesel oil $G_{D O}$, consumption of CNG $G_{C N G}$ 
and the charge in the aspiration manifold. The portion of diesel oil $U_{D O}$ in the engine feeding dose was defined as:

$$
U_{D O}=\frac{Q_{D O}}{Q_{D O}+Q_{C N G}} \cdot 100 \%,
$$

where: $Q_{D O}$ - calorific value of diesel oil; $Q_{C N G}-$ calorific value of $\mathrm{CNG}$.

\section{Results and Discussion}

The tests were conducted at two rates of rotation:

- $1500 \mathrm{rpm}$ - at which the engine controller injects two doses of diesel oil (the pilot dose and the main dose);

- $3400 \mathrm{rpm}$ - at which the controller injects a single dose of fuel regardless of the load.

The engine tests were conducted at these rotation rates for different engine loads $(50 \mathrm{Nm}, 100 \mathrm{Nm}$, $150 \mathrm{Nm}$ ) and different proportions of individual fuels (from 100\% diesel to a minimum amount of diesel for which preset operating parameters could be maintained).

The pressure traces recorded for the rotational rates and loads analysed in the experiment, at different proportions of individual fuels, are presented in Figs 3-7. Examples of current time series recorded on the injector coil are presented in Figs 8-9.

An analysis of these plots shows clearly that the pressure time series during the compression phase depends strongly on the engine load. High pressures obtained for higher loads result from intensive work of the turbine and resulting higher flow rates for air fed to the engine in a cycle and from stronger heating of the charge aspired into the engine. On the other hand, time series for different rotational speeds differ only slightly.

The introduction of even a small dose of gas results in a decrease in the amount of aspired air. The effect is particularly distinct at high rotational speeds, with the reduction of the air mass not being compensated for by the appropriate amount of fed gas. Moreover, it can be noted (Figs 3 and 4) that the effect virtually does not exist at low rotational speeds and a reduction of the amount of fed air results solely from the similar volume of the fed gas. It was found, based on such relationships, that the air depletion is associated with the degree of engine supercharging. The engine supercharging is low at small rotational speeds and it changes only within a small range. At higher speeds, the engine controller detects a reduced load resulting from the additional energy obtained from gas combustion and it reacts by reducing the degree of supercharging. The effect is visible on the recorded pressure time series in Figs 5-7.

The smaller pressures obtained for dual-fuel work resulted from smaller amounts of aspired charge. An analysis of the pressure measurement errors (Fig. 10) showed that the non-repeatability of the engine work cycles is greater when the engine works on CNG compared to single-fuel feeding. The higher levels of errors recorded close to the combustion start point probably resulted from greater dynamics of gas combustion compared to oil combustion. A large increase in heat release from gas combustion resulted in a large error caused by

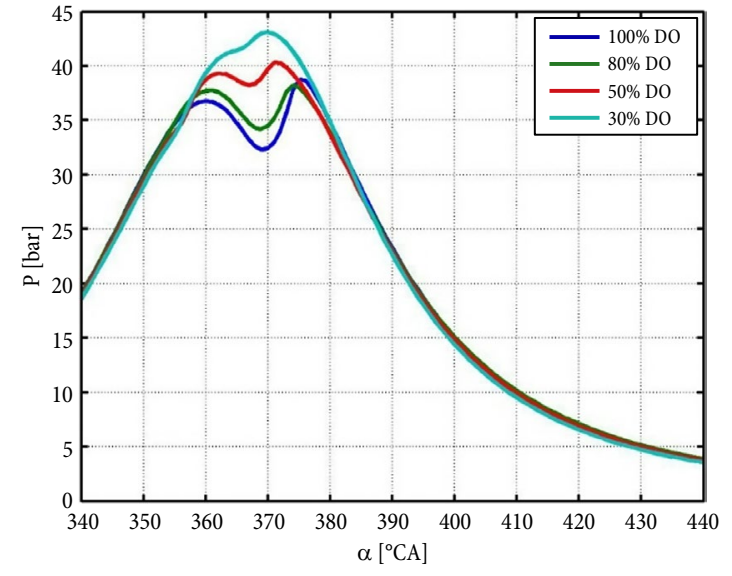

Fig. 3. Average recorded pressure versus CA for dual-fuel operation; $n=1500 \mathrm{rpm} ; T=50 \mathrm{Nm}$ (at different proportions of diesel oil)

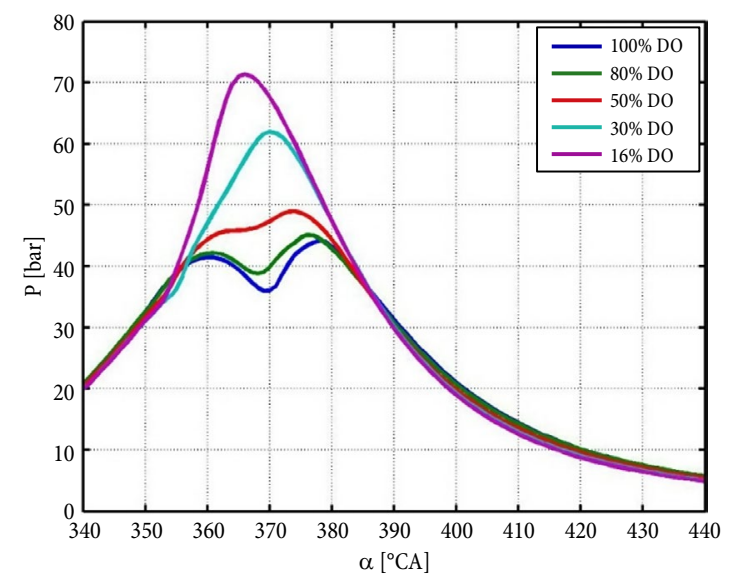

Fig. 4. Average recorded pressure versus CA for dual-fuel operation; $n=1500 \mathrm{rpm} ; T=100 \mathrm{Nm}$ (at different proportions of diesel oil)

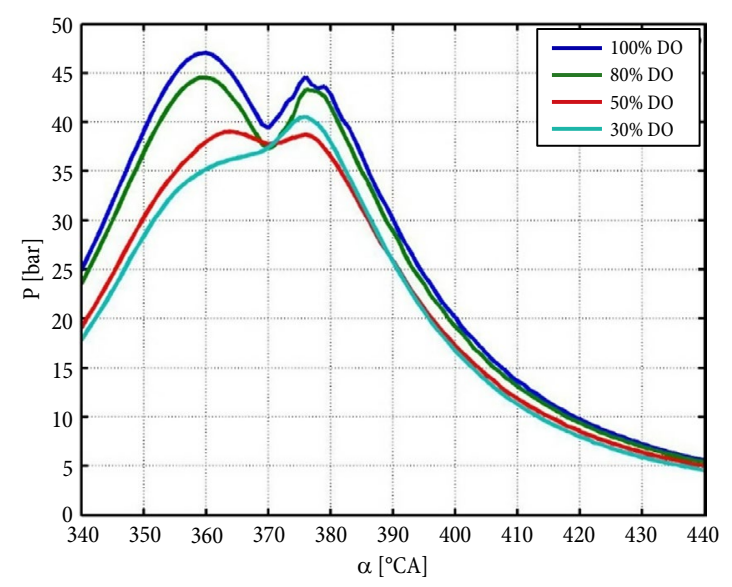

Fig. 5. Average recorded pressure versus CA for dual-fuel operation; $n=3400 \mathrm{rpm} ; T=50 \mathrm{Nm}$ (at different proportions of diesel oil)

even small changes in ignition delay. Interestingly, considerably greater inaccuracies were also observed during the filling phase, which resulted in detectable errors for angles below $350^{\circ} \mathrm{CA}$, with active regulation of the turbine expenditure being its probable cause. 


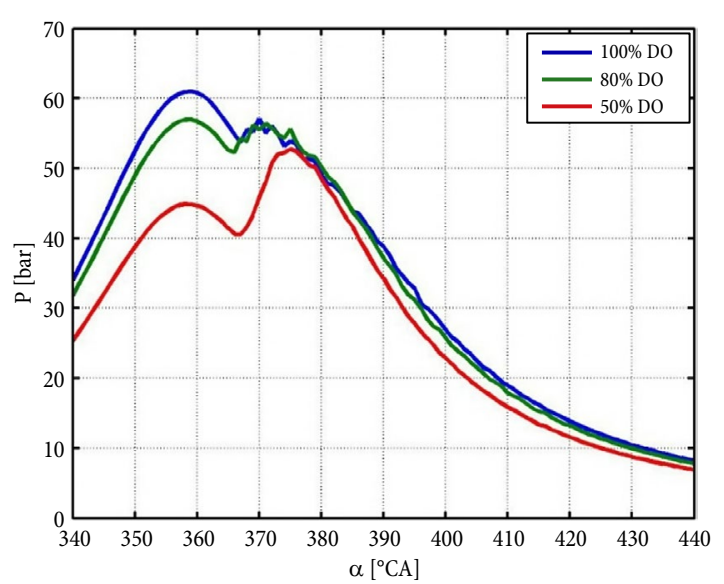

Fig. 6. Average recorded pressure versus CA for dual-fuel operation; $n=3400 \mathrm{rpm} ; T=100 \mathrm{Nm}$ (at different proportions of diesel oil)

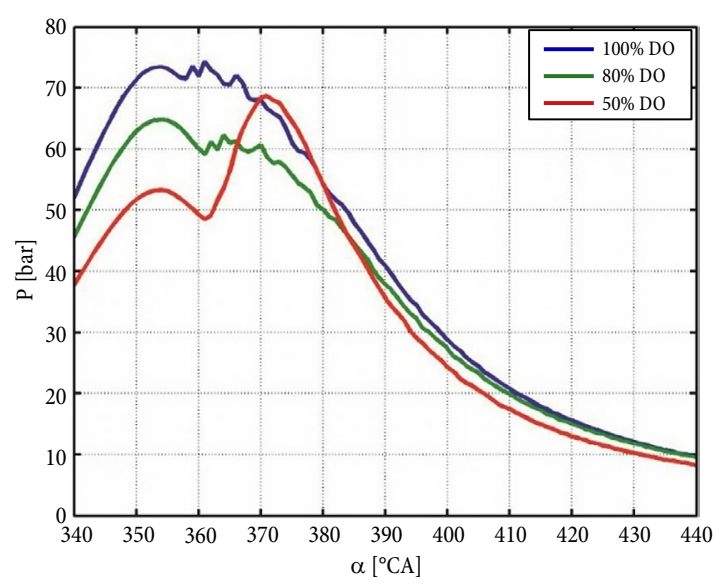

Fig. 7. Average recorded pressure versus CA for dual-fuel operation; $n=3400 \mathrm{rpm} ; T=150 \mathrm{Nm}$ (at different proportions of diesel oil)

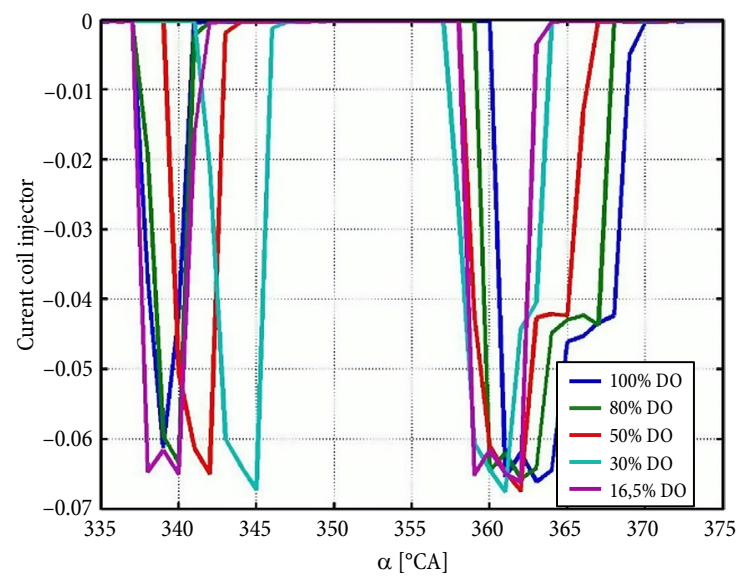

Fig. 8. Injector control current versus CA, $n=1500 \mathrm{rpm}$; $T=100 \mathrm{Nm}$ (different doses of diesel oil)

The compression-ignition delay angle decreased with the rotational speed. It is understandable, considering the fact that if pressure time series are similar, the ignition delay remains highly similar, which means that the angles of combustion start are smaller at lower rotational speeds.

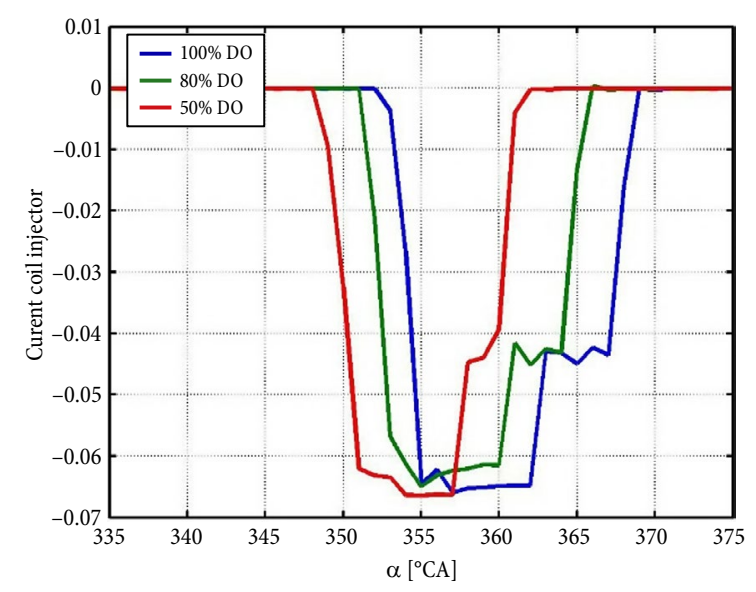

Fig. 9. Injector control current versus CA; $n=3400 \mathrm{rpm}$; $T=100 \mathrm{Nm}$ (different doses of diesel oil)

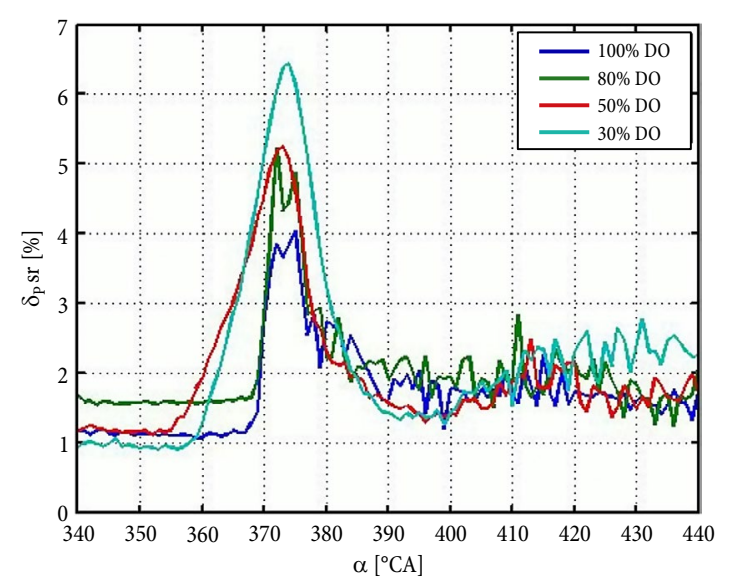

Fig. 10. Average relative error of pressure measurement versus CA; for dual-fuel operation; $n=3400 \mathrm{rpm}$; $T=50 \mathrm{Nm}$ (at different proportions of diesel oil)

An analysis conducted for the rotational speed of $1500 \mathrm{rpm}$ revealed higher pressure values for larger loads, with a dramatic increase for the maximum load. Such high values resulted from high volumetric efficiency $(98 \%)$. This is a sign of a high degree of supercharging, even for low rotational speeds, but at high load.

An analysis of time series for the measurement points, for which the first injection occurs (Fig. 11) allows for easy identification of the point of combustion start - a characteristic maximum of acceleration of the pressure growth.

It was found that for the time series with a divided dose, two extreme of injection characteristics were correlated with two points of combustion start (two local extreme of the second derivative). Fig. 12 shows that combustion of the first dose does not start until $1^{\circ} \mathrm{CA}$ before injection of the main dose. In the other analysed time series, a problem appeared connected with the accuracy of determining both combustion points. Due to the fact that both peaks of combustion were spread along a relatively wide angle range, the point of combustion was determined with a large error, especially in combustion of the first dose. This is shown in Figs 13-14, with numerous peaks of the second derivative with a small 
amplitude for combustion of the first dose. The cause of such a lack of precision becomes clear when derivatives for individual cycles are analysed rather than for an average time series. Large discrepancies in terms of the combustion start points of up to $6^{\circ} \mathrm{CA}$ for the first dose were found in different cycles. Considering the fact that pre-injection takes place very early before the TDC (top dead centre) (that is, for small values of pressure and temperature in the cylinder), the compression-ignition delay is large, which is perfectly clear on Figs 12-14. This has been confirmed by the findings of earlier studies on ignition delay conducted by this author. Small differences in pressure time series at such a long delay generated

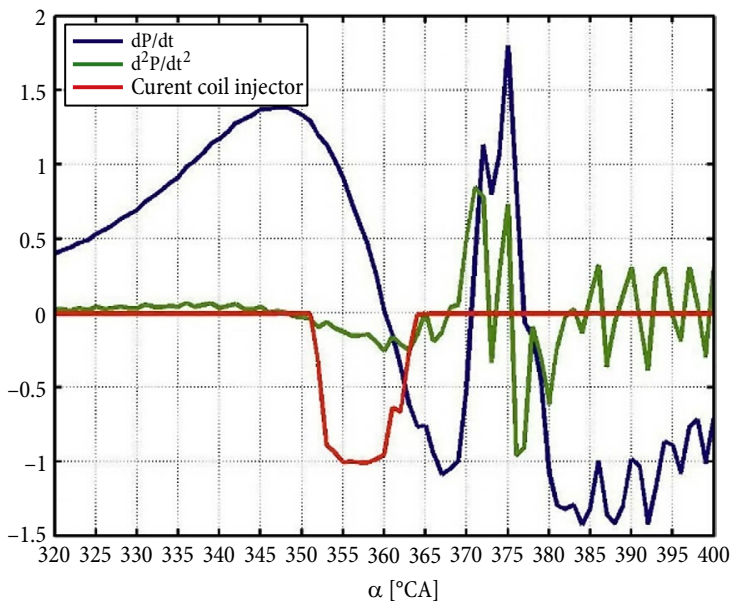

Fig. 11. A juxtaposition of the first and second derivative of pressure in the combustion chamber with injector control current; $n=3400 \mathrm{rpm} ; T=100 \mathrm{Nm} ; U_{D O}=80 \%$ (undivided dose of diesel oil) large differences in the ignition start. For this reason, the precision of determination of the points of combustion start for combustion of two doses of liquid fuel should be treated with reserve. The parameters of injection and the calculated ignition parameters are listed in Table 2.

Tests of NG combustion in engines did not reveal the presence of carbon monoxide in exhaust gases. Therefore, it can be assumed that the gas is completely oxidised. However, under the specific conditions, the entire amount of gas is not burned, with the amount of unburned NG reaching as high as $40 \%$. This is a consequence of the fact that if the mixture being compressed is poor, only the part of the gas, which is in the flame

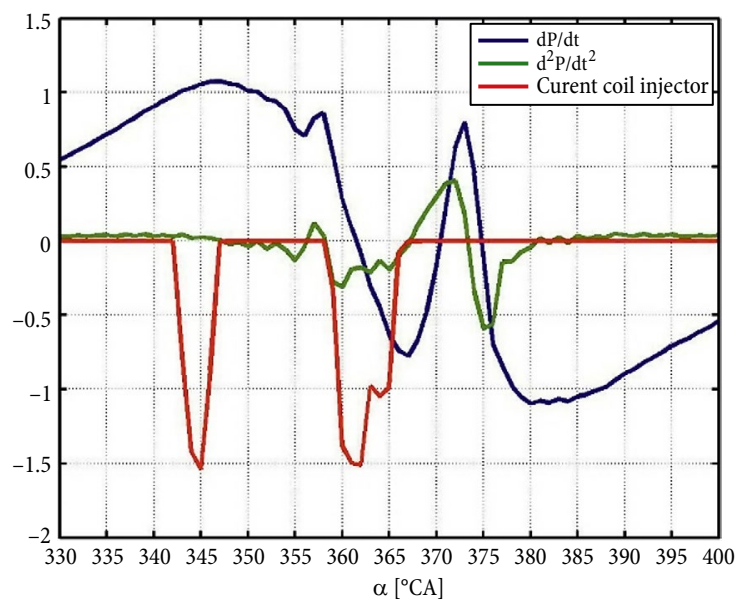

Fig. 12. A juxtaposition of the first and second derivative of pressure in the combustion chamber with injector control current; $n=1500 \mathrm{rpm} ; T=50 \mathrm{Nm} ; U_{D O}=80 \%$ (divided dose of diesel oil)

Table 2. Characteristic parameters of injection of diesel oil and the process of combustion for selected measurement points

\begin{tabular}{|c|c|c|c|c|c|c|}
\hline$n[\mathrm{rpm}]$ & $T[\mathrm{Nm}]$ & $U_{D O}[\%]$ & $\alpha_{i n j \_p}\left[{ }^{\circ} \mathrm{CA}\right]$ & $\alpha_{i n j \_k}\left[{ }^{\circ} \mathrm{CA}\right]$ & $\alpha_{D O \_p}\left[{ }^{\circ} \mathrm{CA}\right]$ & $\alpha_{i d}\left[{ }^{\circ} \mathrm{CA}\right]$ \\
\hline \multicolumn{7}{|c|}{ undivided dose of diesel oil } \\
\hline \multirow{6}{*}{3400} & \multirow{2}{*}{50} & $100 \%$ & 354 & 365 & 369 & 15 \\
\hline & & $80 \%$ & 354 & 363 & 369 & 15 \\
\hline & \multirow{2}{*}{100} & $100 \%$ & 356 & 369 & 368 & 12 \\
\hline & & $80 \%$ & 354 & 366 & 366 & 12 \\
\hline & \multirow{2}{*}{150} & $100 \%$ & 354 & 370 & 364 & 10 \\
\hline & & $80 \%$ & 356 & 370 & 365 & 9 \\
\hline \multicolumn{7}{|c|}{ divided dose of diesel oil } \\
\hline \multirow{10}{*}{1500} & \multirow{10}{*}{100} & \multirow{2}{*}{$100 \%$} & 338 & 341 & 350 & 12 \\
\hline & & & 361 & 369 & 368 & 7 \\
\hline & & \multirow{2}{*}{$80 \%$} & 339 & 341 & 351 & 12 \\
\hline & & & 360 & 368 & 367 & 7 \\
\hline & & \multirow{2}{*}{$50 \%$} & 340 & 343 & 353 & 13 \\
\hline & & & 360 & 367 & 366 & 6 \\
\hline & & \multirow{2}{*}{$30 \%$} & 343 & 346 & 354 & 11 \\
\hline & & & 359 & 364 & 365 & 6 \\
\hline & & \multirow{2}{*}{$17 \%$} & 338 & 342 & 352 & 14 \\
\hline & & & 359 & 364 & 359 & 0 \\
\hline
\end{tabular}

Notes: $\alpha_{i n j \_}-$the angle of the start of injection; $\alpha_{i n j \_}-$the angle of the end of injection; $\alpha_{D O \_}-$the start of diesel oil ignition; $\alpha_{i d}$ - the diesel oil ignition delay angle. 


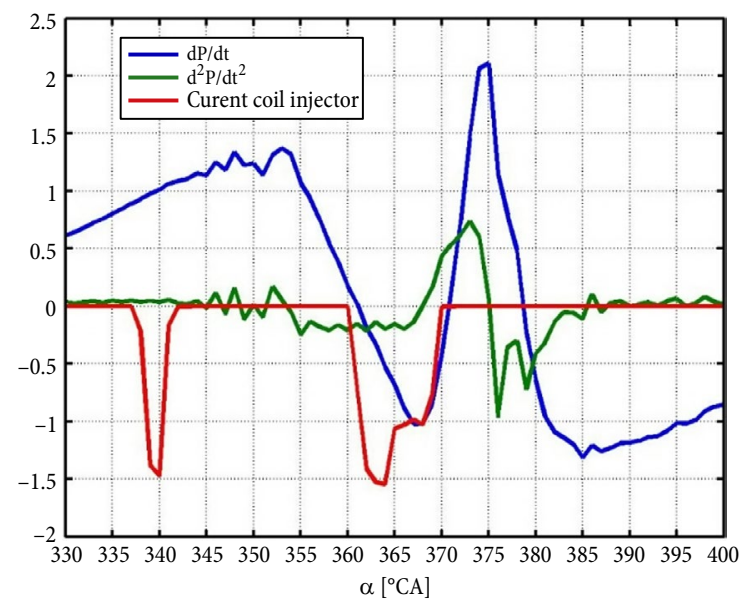

Fig. 13. A juxtaposition of the time series of the first and second derivative of the pressure in the combustion chamber with the time series of the injector controlling impulse; $n=1500 \mathrm{rpm} ; T=100 \mathrm{Nm} ; U_{D O}=80 \%$ (divided dose of diesel oil)

zone of the burning diesel oil will be burned. This is why it is so important to determine what amount of gas takes part in the reaction.

The degree of utilisation of CNG in the process of combustion was assessed by means of the energy criterion. By comparison of the amount of energy fed in fuel in single-fuel work $Q_{1 f}$ and the total amount of energy fed in liquid fuel $Q_{2 f D O}$ and gaseous fuel $Q_{2 f C N G}$, with the same working conditions and dual-fuel feeding, it is possible to estimate the percentage of gaseous fuel, which takes part in the process of combustion. Therefore, the theoretical degree of utilisation of $\mathrm{CNG}\left(\xi_{\mathrm{CNG}}\right)$ can be noted as:

$$
\xi_{C N G}=\frac{Q_{2 f C N G}+Q_{2 f D O}}{Q_{1 f}} .
$$

The results of the comparison were presented in Table 3 together with the parameters, which characterise the charge.

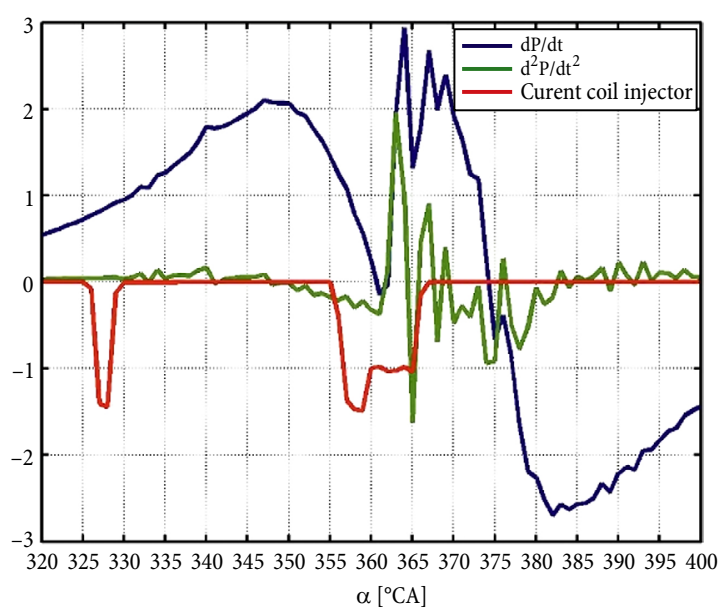

Fig. 14. A juxtaposition of the first and second derivative of pressure in the combustion chamber with injector control current; $n=1500 \mathrm{rpm} ; T=200 \mathrm{Nm} ; U_{D O}=50 \%$

(divided dose of diesel oil)

An analysis of the energy aspects of the experiment leads to the conclusion that the amount of gas which takes part in the reaction changes within a wide range from $98 \%$ to $65 \%$. For a single dose, gas combustion takes place under conditions defined by the $\lambda$ coefficient. For a divided dose, combustion of NG takes place after injection of a very small initiating dose of diesel oil, i.e. under conditions better described by the $\lambda_{C N G}$ parameter. This has been confirmed by a study conducted by (Stelmasiak 2003), who claimed that the percentage of burned NG increases with its growing concentration in the compressed mixture. The best conditions for burning methane in a multi-fuel engine were identified for an air excess index ranging from 1.8 to 2.2 , which corresponds to the lower limit of flammability of methane under the operating conditions of an engine. The results were similar to the propositions of (Badr et al. 1999), who achieved the best conditions of combustion for $\lambda$ ranging from 2.0 to 2.4 .

Table 3. Parameters which characterise the charge in the combustion chamber for selected measurement samples

\begin{tabular}{|c|c|c|c|c|c|c|c|c|c|c|c|c|}
\hline $\begin{array}{c}n \\
{[\mathrm{rpm}]}\end{array}$ & $\begin{array}{c}T \\
{[\mathrm{Nm}]}\end{array}$ & $\begin{array}{l}U_{D O} \\
{[\%]}\end{array}$ & $\begin{array}{c}G_{p} \\
{[\mathrm{~kg} / \mathrm{h}]}\end{array}$ & $\begin{array}{c}G_{D O} \\
{[\mathrm{~kg} / \mathrm{h}]}\end{array}$ & $\begin{array}{c}G_{c n g} \\
{[\mathrm{~kg} / \mathrm{h}]}\end{array}$ & $\lambda_{D O}$ & $\lambda_{C N G}$ & $\lambda$ & $\begin{array}{c}\mathrm{Q}_{1 f} \\
{[\mathrm{MJ} / \mathrm{kg}]}\end{array}$ & $\begin{array}{c}\mathrm{Q}_{2 f_{-} D O} \\
{[\mathrm{MJ} / \mathrm{kg}]}\end{array}$ & $\begin{array}{l}\mathrm{Q}_{2 \mathrm{f} \_C N G} \\
{[\mathrm{MJ} / \mathrm{kg}]}\end{array}$ & $\xi_{C N G}$ \\
\hline \multicolumn{13}{|c|}{ Undivided dose of diesel oil } \\
\hline \multirow{3}{*}{3400} & 50 & \multirow{3}{*}{$80 \%$} & 263 & 7.6 & 1.3 & 2.7 & 11.0 & 2.2 & 319.2 & 256.2 & 64.3 & 0.98 \\
\hline & 100 & & 300 & 9.1 & 2.2 & 2.3 & 7.8 & 1.8 & 478.8 & 382.2 & 111.4 & 0.87 \\
\hline & 150 & & 325 & 12.5 & 3.6 & 1.8 & 5.3 & 1.3 & 646.8 & 525.0 & 178.9 & 0.68 \\
\hline \multicolumn{13}{|c|}{ Divided dose of diesel oil } \\
\hline \multirow{4}{*}{1500} & \multirow{4}{*}{100} & $80 \%$ & 106 & 3.3 & 1.0 & 2.2 & 6.0 & 1.6 & 172.2 & 138.6 & 51.4 & 0.65 \\
\hline & & $50 \%$ & 102.5 & 2.1 & 2.1 & 3.4 & 2.8 & 1.5 & 172.2 & 88.2 & 107.1 & 0.78 \\
\hline & & $30 \%$ & 99.5 & 1.2 & 2.8 & 5.7 & 2.0 & 1.5 & 172.2 & 50.4 & 141.4 & 0.86 \\
\hline & & $16 \%$ & 98 & 0.7 & 3.2 & 9.9 & 1.8 & 1.5 & 172.2 & 28.6 & 158.5 & 0.91 \\
\hline
\end{tabular}

Notes: $\lambda$ - global air/fuel ratio; $\lambda_{C N G}-$ air/fuel ratio for the CNG-air mixture; $\lambda_{D O}-$ air/fuel ratio relative to diesel oil. 


\section{Conclusions}

The study results showed that the non-repeatability of an engine operation increases when an engine operates in a dual-fuel mode. Stable operation with larger doses of gaseous fuel can be achieved only at lower rotational speeds.

The experiment showed that gas does not burn completely in a dual-fuel engine. However, this does not result from incomplete burning of CNG, but rather from the fact that the entire amount of this fuel does not take part in the reaction. Moreover, the best conditions for combustion are ensured with the air excess index $\lambda$ of about 2, i.e. for higher concentrations of the gaseous fuel.

An analysis of the time series of the second derivative of pressure shows that gas ignition does not always take place simultaneously with diesel oil ignition. In some cases it is delayed by the angle which is a consequence of flame development in the gas mixture. Strong fluctuations of the combustion start point are also observed, which considerably increases the engine operation non-repeatability.

Gas ignition in a divided dose probably takes place at two points, as in diesel oil. If the gas concentration lies close to the lower limit of flammability, only the part of gas covered by the diesel oil combustion zone is burned.

The study has clearly shown that even a relatively small addition of CNG ranging from 20 to $40 \%$, with a standard system of diesel oil injection control in place, changes the pressure time series considerably. Presumably, with such a solution, not only do the emission levels of toxic compounds to the atmosphere change, but also the thermal load of the engine and the mechanical load on the crankshaft-piston system.

\section{References}

Aesoy, V.; Valland, H. 1996. Hot surface assisted compression ignition of natural gas in a direct injection diesel engine, SAE Technical Paper 960767.

http://dx.doi.org/10.4271/960767

Assanis, D. N.; Filipi, Z. S.; Fiveland, S. B.; Syrimis, M. 2003. A predictive ignition delay correlation under steady-state and transient operation of a direct injection diesel engine, Journal of Engineering for Gas Turbines and Power 125(2): 450-457. http://dx.doi.org/10.1115/1.1563238

Azimov, U.; Tomita, E.; Kawahara, N.; Dol, S. S. 2012. Combustion characteristics of syngas and natural gas in micropilot ignited dual-fuel engine, International Science Index 6(12): 1595-1602.

Badr, O.; Karim, G. A.; Liu, B. 1999. An examination of the flame spread limits in a dual fuel engine, Applied Thermal Engineering 19(10): 1071-1080. http://dx.doi.org/10.1016/S1359-4311(98)00108-2

BP p.l.c. 2013. BP Energy Outlook 2030. London, United Kingdom. 86 p. Available from Internet: http://www.bp.com/ content/dam/bp/pdf/Energy-economics/Energy-Outlook/ BP_Energy_Outlook_Booklet_2013.pdf

Carlucci, P.; Ficarella, A.; Laforgia, D. 2003. Effects of pilot injection parameters on combustion for common rail diesel engines, SAE Technical Paper 2003-01-0700.

http://dx.doi.org/10.4271/2003-01-0700
Czerwinski, J.; Comte, P. 2001. Influences of gas quality on a natural gas engine, SAE Technical Paper 2001-01-1194. http://dx.doi.org/10.4271/2001-01-1194

Doijode, E. D.; Tewari, P.; Basavarajappa, Y. H.; Banapurmath, N. R.; Yaliwal, V. S. 2013. Experimental studies on manifold injected CNG-biodiesel dual fuel engine, International Journal of Emerging Technology and Advanced Engineering 3(3): 77-83.

Goto, S.; Lee D.; Harayama, N.; Honjo, F.; Ueno, H.; Honma, H.; Wakao, Y.; Mori, M. 2000. Development of LPG SI and CI engines for heavy duty vehicles, in FISITA 2000 World Automotive Congress, 12-15 June 2000, Seoul, Korea, 1-9.

ISO 1585:2010. Road Vehicles - Engine Test Code - Net Power. Jemni, M. A.; Kantchev, G.; Abid, M. S. 2011. Influence of intake manifold design on in-cylinder flow and engine performances in a bus diesel engine converted to LPG gas fuelled, using CFD analyses and experimental investigations, Energy 36(5): 2701-2715.

http://dx.doi.org/10.1016/j.energy.2011.02.011

Karim, G.; Jones, W.; Raine, R. 1989. An examination of the ignition delay period in dual fuel engines, SAE Technical Paper 892140. http://dx.doi.org/10.4271/892140

Korakianitis, T.; Namasivayam, A. M.; Crookes, R. J. 2011. Diesel and rapeseed methyl ester (RME) pilot fuels for hydrogen and natural gas dual-fuel combustion in compression-ignition engines, Fuel 90(7): 2384-2395. http://dx.doi.org/10.1016/j.fuel.2011.03.005

Liu, Z.; Karim, G. 1995. The Ignition delay period in dual fuel engines, SAE Technical Paper 950466.

http://dx.doi.org/10.4271/950466

Makarevičienè, V.; Sendžikienė, E.; Pukalskas, S.; Rimkus, A.; Vègneris, R. 2013. Performance and emission characteristics of biogas used in diesel engine operation, Energy Conversion and Management 75: 224-233. http://dx.doi.org/10.1016/j.enconman.2013.06.012

Motyl, K.; Lisowski, M. 2008. Wpływ temperatury początkowej i składu mieszaniny palnej na pracę silnika HCCI zasilanego biogazem, Inżynieria Rolnicza (1): 311-317. (in Polish).

Piętak, A.; Mikulski, M. 2011. On the modeling of pilot dose ignition delay in a dual-fuel, self ignition engine, Combustion Engines (3): 94-102.

Raine, R. 1990. A performance model of the dual fuel (diesel/ natural gas) engine, SAE Technical Paper 900387. http://dx.doi.org/10.4271/900387

Ray, N. H. S.; Mohanty, M. K.; Mohanty, R. C. 2013. A study on application of biogas as fuel in compression ignition engines, International Journal of Innovations in Engineering and Technology 3(1): 239-245.

Saito, H.; Kawabata, Y.; Sakurai, T. 2000. Study on the Lean Burn Gas Engine Ignited by Pilot Fuel Injection. Part 4. Annual Technical Report Digest No 10.

Saito, H.; Kawabata, Y.; Sakurai, T. 1999. Study on the Lean Burn Gas Engine Ignited by Pilot Fuel Injection. Part 3. Annual Technical Report Digest No 9.

Saleh, H. E. 2008. Effect of variation in LPG composition on emissions and performance in a dual fuel diesel engine, Fuel 87(13-14): 3031-3039. http://dx.doi.org/10.1016/j.fuel.2008.04.007

Semin A. R. I.; Bakar, R. A. 2009. Gas fuel spray simulation of port injection compressed natural gas engine using injector nozzle multi holes, European Journal of Scientific Research 29(2): 188-193. 
Semin, A. R. I.; Idris A.; Bakar, R. A. 2009. Effect of port injection CNG engine using injector nozzle multi holes on air-fuel mixing in combustion chamber, European Journal of Scientific Research 34(1): 16-24.

Stelmasiak, Z. 2004. Combustion with low $\mathrm{NO}_{\mathrm{x}}$ and smokeless in a dual-fuel diesel engine fuelled with natural gas as main fuel, Journal of KONES 11(3-4): 218-225.

Stelmasiak, Z. 2003. Studium procesu spalania $w d w u$-paliwowym silniku o zapłonie samoczynnym zasilanym gazem ziemnym i olejem napędowym. Wydawnictwo Akademii Techniczno-Humanistycznej w Bielsku Białej. (in Polish).

Wierzbicki, S. 2014. Laboratory control and measurement system of a dual-fuel compression ignition combustion engine operating in a cogeneration system, Solid State Phenomena 210: 200-205.

http://dx.doi.org/10.4028/www.scientific.net/SSP.210.200

Yao, M. F.; Zhang, Q. C.; Zheng, Z. Q.; Zhang, P. 2009. Experimental study of effects of oxygen concentration on combustion and emissions of diesel engine, Science in China Series E: Technological Sciences 52(6): 1527-1534.

http://dx.doi.org/10.1007/s11431-009-0173-6 